\title{
Artificial Neural Network Turbulent Modeling for Predicting the Pressure Drop of Nanofluid
}

\author{
M. S. Youssef \\ Mechanical Engineering Department, Faculty of Engineering, Taif University, Al-Haweiah, P.O. Box 888, Saudi \\ Arabia \\ E-mail: youssef2056@yahoo.com
}

Ayman A. Aly

Permanent Address: Mechanical Engineering Department, Faculty of Engineering, Assiut University, Assiut P.O. Box 71516, Egypt

\begin{abstract}
An Artificial Neural Network (ANN) model was developed to predict the pressure drop of titanium dioxide-water $\left(\mathrm{TiO}_{2}\right.$-water). The model was developed based on experimentally measured data. Experimental measurements of fully developed turbulent flow in pipe at different particle volumetric concentrations, nanoparticle diameters, nanofluid temperature and Reynolds number were used to construct the proposed model. The ANN model was validated by comparing the predicted results with the experimental measured data at different experimental conditions. It was shown that, the present ANN model performed well in predicting the pressure drop of $\mathrm{TiO}_{2}$-water nanofluid under different flow conditions with a high degree of accuracy.
\end{abstract}

Index Terms - Nanofluids, Particle Concentration, Turbulent Flow, Pressure Drop, Artificial Neural Network

\section{Introduction}

Nanofluid is the name conceived by Argonne National Laboratory to describe a fluid in which nanometer-sized solid particles, fibers, or tubes are suspended in liquids such as water, engine oil, and ethylene glycol(EG). Many industrial processes involve the transfer of heat by means of a flowing fluid in either the laminar or turbulent regime as well as flowing or stagnant boiling fluids. Many of these processes would benefit from a decrease in the thermal resistance of the heat transfer fluid. Correspondingly, smaller heat transfer systems with lower capital cost and improved thermal efficiencies would result. Nanofluids have the potential to reduce such thermal resistances and can be used in different industrial applications such as electronics, transportation, medical, food, and manufacturing industry of many types (Yu et al., 2007).

While thermal properties are important for heat transfer applications, the viscosity is also important in designing nanofluids for flow and heat transfer applications because the pressure drop and the resulting pumping power depend on the viscosity. Many experimental investigations on the heat transfer performance and pressure drop of different nanofluids with various nanoparticle volume concentrations, in both laminar and turbulent flow regimes, have been reported (Ko et al., 2007; He et al., 2007; Peng et al., 2009; Duangthongsuk and Wongwises, 2009; Duangthongsuk and Wongwises, 2010; Fotukain and Esfahany, 2010; Vajjha et al., 2010; Teng et al., 2011; and Sajadi and Kazemi 2011). The results of Duangthongsuk and Wongwises (2010) showed that the pressure drop of nanofluids was slightly higher than the base fluid and increases with increasing the volume concentrations. Also, the results of Duangthongsuk and Wongwises (2009) and He et al. (2007) disclosed that the pressure drop of the nanofluids was very close to that of the base fluid. Ko et al. (2007) experimentally measured the pressure drop of nanofluids containing carbon nanotubes flowing through a horizontal tube under laminar and turbulent flow conditions. Their results revealed significant increase in pressure drop on nanofluids under laminar flow condition, while, the pressure drop of nanofluids presented similar values to those of the base fluid at the turbulent flow conditions. In another article published by Teng et al. (2011) results show that the enhancement of pressure drop for $\mathrm{TiO}_{2}$ nanofluid was lower under turbulent flow conditions in a circular pipe but higher under laminar flow conditions. Recently, turbulent heat transfer behavior of titanium dioxide/water nanofluid in a circular pipe under fullydeveloped turbulent regime for various volumetric concentrations was investigated experimentally by Sajadi and Kazemi (2011). Their measurements showed that the pressure drop of nanofluid was slightly higher than that of the base fluid and increased with increasing the volume concentration. In contrast, the results of Fotukian and Esfahany (2010) indicated that the maximu $m$ increase in pressure drop was about $20 \%$ for nanofluid. In the same trend, the experimental results of Peng et al. (2009) showed that the frictional pressure 
drop of refrigerant-based nanofluid increases with the increase of the mass fraction of nanoparticles, and the maximum enhancement of frictional pressure drop was $20.8 \%$ under their experimental conditions. Moreover, Vajjha et al. (2010) reported that the pressure loss of nanofluids increased with an increase in particle volume concentrations and the increase of pressure loss for a $10 \% \mathrm{Al}_{2} \mathrm{O}_{3}$ nanofluid was about 4.7 times that of the base fluid. Summarizing what is reviewed in the experimental studies, one could easily conclude that, the variation in the experimental data of the pressure drop of nanofluids is attributed to the difficulties of the experimental measurements. These difficulties arise due to lack in understanding the details and mechanis ms of heat transfer phenomenon that change the thermal conductivity and pressure drop in nanofluids (Kondaraju et al., 2010).

Various analytical and numerical models were proposed to study the mechanism and predict the thermal conductivity and pressure drop of different nanofluids (Namburu et al., 2009; Fard et al., 2010; and Demir et al., 2011). The numerical studies of nanofluids can be conducted using single-phase (homogenous) or two-phase approaches. In the former approach it is assumed that the fluid phase and nanoparticles are in thermal equilibrium with zero relative velocity. While, in the latter approach, base fluid (liquid) and nanoparticles (solid) are considered as two different phases with different momentums respectively (Fard et al., 2010). Some of the published articles were related to investigation of laminar convective heat transfer of nanofluids (Fard et al., 2010, and Demir et al., 2011), while, the others were concerning with turbulent ones (Namburu et al., 2009). Fard et al. (2010) used Computational Fluid Dynamics (CFD) approach regarding single-phase and two-phase models to study laminar convective heat transfer of nanofluids with different volu me concentration in a circular tube. Their numerical results have clearly shown that nanofluids with higher volu me concentration have higher pressure drop and two-phase model showed better agreement with experimental data. Commercial CFD package, FLUENT, was used by Demir et al. (2011) for solving the volume-averaged continuity, momentum, and energy equations of different nanofluids flowing in a horizontal tube under constant temperature condition. Their numerical results have clearly indicated that pressure drop increased with increasing the particle loading parameter and Reynolds number because of increasing velocity and viscosity of nanofluid. Turbulent flow and heat transfer of three different nanofluids flowing through a circular tube under constant heat flux condition have been numerically analyzed by Namburu et al. (2009). They assumed single-phase fluid model to solve two-dimensional steady, forced turbulent convection flow of nanofluid flowing inside a straight circular tube. Two-equation turbulence model of Launder and Spald ing was adopted by Namburu et al. (2009) in their numerical analysis. Their computed results indicated that pressure loss increased with increase in the volume concentration of nanofluids.

Based on the preceding literature review of numerical algorithms, one could conclude that, the algorithms employed in numerical studies particularly with turbulent flows are usually complicated since they involve the solution of complex differential equations. As a corollary, these programs usually require large computing power and need a considerable amount of time to give accurate predictions. Therefore, instead of carrying out experimental measurements or using complex algorithms and mathematical routines to determine the pressure drop of nanofluids, a simple and accurate model is desirable. The objective of the present study is to develop an Artificial Neural Network (ANN) model to predict the pressure drop of nanofluid at different particle volumetric concentrations, nanoparticle diameters, nanofluid temperatures and different values of Reynolds number. Titan iu m dioxide dispersed in water $\left(\mathrm{TiO}_{2} /\right.$ water $)$ was selected as a sample-nanofluid due to their abundant experimental data to assess the proposed ANN model.

\section{Theoretical Background of Pressure Drop}

Pressure drop during the flow is one of the important parameters determining the efficiency of nanofluids application. Pressure drop and nanofluid pumping power are closely associated with each other (Saidur et al., 2011). It is expected that pressure drop, $\Delta \mathrm{P}$, of the nanofluid flowing in a pipe depends upon a number of factors such as density and viscosity of the nanofluid, diameter of the pipe, the volume fraction of the suspended particles, the flow pattern, the dimensions and the shape of the suspended particles. To our knowledge, there are no published literatures on deriving the pressure drop correlation of the nanofluid from either theoretical or experimental approach. Therefore, some theoretical equations related to base fluids or conventional fluids are cited here and the following expression is used to determine the pressure drop in a horizontal pipe (He et al., 2007; and Vajjha et al., 2010).

$$
\Delta \mathrm{P}=\frac{2 \mathrm{f} \rho \mathrm{v}^{2} \mathrm{~L}}{D}
$$

where $\Delta \mathrm{P}$ is the pressure drop, $\mathrm{f}$ is the friction factor, $\rho$ is the density of fluid, $v$ is the average velocity of flow, $\mathrm{L}$ is the length of tube where the pressure drop is determined, $\mathrm{D}$ is the inside diameter of tube. In turbulent flow regime, the friction factor $f$ is determined from the so-called Blasius equation as follows (Vajjha et al., 2010).

$$
\mathrm{f}=0.078 \operatorname{Re}^{-0.25}
$$


Substituting from Eq. (2) into Eq. (1), the following equation for the pressure drop is obtained.

$$
\Delta \mathrm{P}=0.156\left(\frac{\mathrm{L} \mu^{2}}{\rho D^{3}}\right) \operatorname{Re}^{1.75}
$$

where $\mu$ and $\operatorname{Re}$ are the absolute viscosity of flu id and Reynolds number of flow, respectively. The output data from Eq. (3) will be used for comparison with both the predicted pressure drop values from the ANN model and the experimental measurements as will be seen later.

\section{Artificial Neural Network (ANN) Model Principles}

\subsection{ANN Model Structure}

Artificial neural networks (ANNs) are computational model constructed of many simple interconnected elements called neurons, which is based on the information processing system of the human brain. Figure 1 shows the architecture of the neural network model used in this work. The basic structure is a multilayer A NN model where the chosen four inputs are fed into the first layer of hidden units. The circles represent the neurons (weights, bias, and activation functions) and the lines represent the connections between the inputs and neurons, and between the neurons in one layer and those in the next layer. Several studies have found that a three-layered neural network, where there are three stages of neural processing between the inputs and outputs, can approximate any nonlinear function to any desired accuracy (Hsu et al., 1995; Aly, 2007; and Kurt and Kayfeci, 2009). Each layer consists of units which receive their input from units from a layer directly below and send their output to units in a layer directly above the unit. Each connection to a neuron has an adjustable weighting factor associated with it. The output of the hidden units is distributed over the next layer of hidden units, until the last layer of hidden units, of which the outputs are fed into a layer of no output units. Training of the ANN model typically implies adjustments of connection weights and biases so that the differences between ANN outputs and desired outputs are minimized.

\subsection{Back-propagation Training Algorithm}

Back-propagation training, used in this investigation, is one of the most popular ANN training methods. The basic back-propagation algorithm adjusts the weights in the steepest descent direction (negative of the gradient). This is the direction in which the error decreases most rapidly. To explain the back-propagation rule in detail, the three-layer network shown in Fig. 1 will be used. The training phase is divided into two phases as follows:
1. Forward-propagation phase: In the first phase, input data are sent from the input layer to the output layer, i.e., $x=[x 1: x 4]$ propagate from the input layer to the output layer $y$.

$$
\begin{aligned}
& Z_{q}=f\left(\sum_{j} V_{q j} x_{j}\right) \\
& y_{i}=f\left(\sum_{q} W_{i q} Z_{q}\right)
\end{aligned}
$$

where $W_{i q}$ and $V_{q j}$ represent weights in the hidden-tooutput and input-to-hidden connections, respectively.

2. Back-propagation phase: In the second phase, the errors between target outputs, $\mathrm{d}$, and predicted outputs, y, are calculated and propagated backwards to the input layer in order to change the weights of hidden layers by using the gradient descent method.

The algorithm tries to minimize the objective function, i.e. the least square error between the predicted and the target outputs, which is given by:

$$
E=\frac{1}{2} \sum_{p}\left(d_{o}{ }^{p}-y_{o}{ }^{p}\right)^{2}
$$

where $p$ represents the number of training datasets and $O$ represents the number of output nodes. Then the algorith $m$ uses the steepest-descent direction to adjust the weights in the hidden-to-output and input-to-hidden connections and as follows:

$$
\Delta W_{i q}=-\lambda \frac{\partial E}{\partial W_{i q}}, \Delta V_{q j i}=-\lambda \frac{\partial E}{\partial V_{q j}}
$$

where $\lambda$ is the learning rate.

Since this algorithm requires a learning rate parameter to determine the extent to which the weights change during iteration, i.e., the step sizes, its performance depends on the choice of the value of the learning rate. The two phases are iterated until the performance error is decreased to certain desirable range (Hsu et al., 1995; Aly, 2007; and Kurt and Kayfeci, 2009).

\subsection{Activation Functions}

Activation functions are used in ANNs to produce continuous values rather than discrete ones. The activation functions used in hidden layer neurons are tan sigmoid functions and the piecewise linear activation function is used for the last layer neurons. The logistic activation function or more popularly 
referred to as the sigmoid function is semi-linear in character, differentiable and produces a value between 0 and 1. The mathematical expression of this sigmoid function is:

$$
f\left(\text { net }_{j}\right)=\frac{1}{1+e^{-c\left(n e t_{j}\right)}}
$$

and when is c small, the sig moid becomes more like a straight line (linear). When $\mathrm{c}$ is large, learning is much faster but a lot of in formation is lost, however when $c$ is small, learning is very slow but information is retained. Because this function is differentiable, it enables the back-propagation algorithm to adapt the lower layers of weights in a multilayer neural network.

where $c$ controls the firing angle of the sig moid. When $\mathrm{c}$ is large, the sigmoid becomes like a threshold function

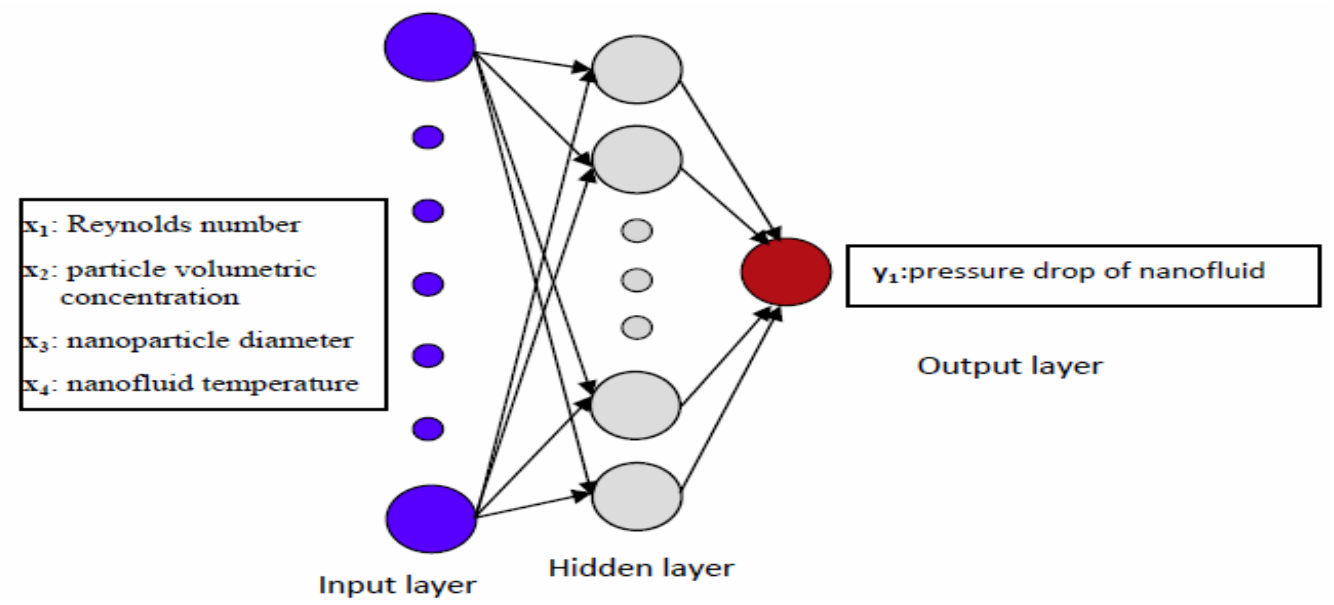

Fig. 1: A schematic of neural network model

\section{ANN Model}

In the present study, the effects of four independent parameters on the pressure drops of Titanium dioxide dispersed in water $\left(\mathrm{TiO}_{2} /\right.$ water)flowing through a pipe under turbulent flow regime was investigated. These four independent parameters are the particle volu metric concentration in nanofluid, temperature of nanofluid, nanoparticle diameter, and Reynolds number of flow. Values of these four inputs are fed into the hidden layer. Each connection to a neuron has adjustable weighting factor associated with it. The outputs of the hidden layer are fed into a layer of one output units which is the pressure drop $\Delta \mathrm{P}$ of nanofluid. The activation functions in hidden layer neurons are tan sigmoid functions and the piecewise linear activation function is used for the last layer neurons. The algorithm tries to minimize the objective function, i.e. the least square error between the predicted and the target outputs. Several neural network models were trained with various designs including nu mber of hidden layers and number of nodes in each hidden layer. The selection of the optimum model was based on minimizing the difference between the neural network results and the desired output. It was found that, best structure of the ANN model had an input layer, a hidden layer and an output layer. Therefore, the developed ANN architecture had a configuration as shown in Fig. 1. The input layer comprises all of the four input variables, which are connected to neurons in the hidden layer through the weights assigned for each link. The number of neurons in the hidden layer is found by optimizing the network. All the four input parameters and their range of values of Titanium dioxide dispersed in water $\left(\mathrm{TiO}_{2} /\right.$ water $)$ used to develop the neural network model are mentioned in Table 1.

Table 1: The range of input parameters and experimental data set used in training and testing the proposed ANN model [Duangth ongsuk and Wongwises, 2009; Duangthongsuk and Wongwises, 2010, and He et al., 2007]

\begin{tabular}{|c|c|c|c|}
\hline Input variable & $\begin{array}{c}\text { Duangthongsuk and } \\
\text { Wongwise (2010) }\end{array}$ & $\begin{array}{c}\text { Duangthongsuk Wongwise } \\
(\mathbf{2 0 0 9})\end{array}$ & $\begin{array}{c}\text { He et al. } \\
(\mathbf{2 0 0 7})\end{array}$ \\
\hline Reynolds number range & $3800-12300$ & $4000-16400$ & $2300-6000$ \\
\hline Particle volumetric concentration, $\phi$ & $0 \%, 0.2 \%, 0.6 \%, 1.0 \%, 1.5 \%$ & $0 \%, 0.2 \%$ & $0 \%, 0.24 \%, 0.6 \%$ \\
\hline Nanoparticle diameter & $21 \mathrm{~nm}$ & $21 \mathrm{~nm}$ & $95 \mathrm{~nm}$ \\
\hline Nano fluid temperature & $15^{\circ} \mathrm{C}$ & $15,20,25{ }^{\circ} \mathrm{C}$ & $22^{\circ} \mathrm{C}$ \\
\hline Experimental data set & $40($ for training) & $48(32$ for training and 16 for testing) & 18 (for training) \\
\hline
\end{tabular}




\section{Results and Discussions}

The developed ANN model was trained using the measured data of $\mathrm{TiO}_{2}$-water obtained from the experiments for pressure drop $\Delta \mathrm{P}$. The experimental data set consisted of 106 values as shown in Table 1 . These values were divided into two groups, of which 90 values were used for training/learning of the ANN model. This means that the experimental data of Duangthongsuk and Wongwises (2010), the experimental data of Duangthongsuk and Wongwises (2009) at $20{ }^{\circ} \mathrm{C}$ and $25^{\circ} \mathrm{C}$, as well as the experimental data of He et al. (2007) were used for training of the proposed model. On the other hand, 16 values of the experimental data of Duangthongsuk and Wongwises (2009) at $15^{\circ} \mathrm{C}$ of nanoflu id temperature were chosen to validate the proposed ANN model. The results of training and validation of the developed ANN model are explained and discussed in the following two sections.

\subsection{Results of Training}

A sets of 90 values obtained from the experimental data have been used to train the developed ANN model. Details of these data sets are found in Table 1. Figure 2 shows the distribution of the ANN predicted pressure drop $\Delta \mathrm{P}$ for $21 \mathrm{~nm}$ nanoparticle at $15{ }^{\circ} \mathrm{C}$ temperature of $\mathrm{TiO}_{2}$ along with the experimentally measured values of Duangthongsuk and Wongwises (2010) at the same conditions. Excellent agreement is found between the trained values of the model and both the experimental measurements of Duangthongsuk and Wongwises (2010) and the calculated values from the theoretical equation of pressure drop. Variations of the ANN predicted pressure drop with the Reynolds number for $21 \mathrm{~nm}$ nanoparticle at $20{ }^{\circ} \mathrm{C}$ and $25{ }^{\circ} \mathrm{C}$ nanofluid te mperatures as well as for $95 \mathrm{~nm}$ nanoparticle at $22{ }^{\circ} \mathrm{C}$ nanofluid temperature are shown in Figure 3 and Figure 4, respectively. Also, included in these figures are the experimental measurements of Duangthongsuk and Wongwises (2009) and He et al. (2007) as well as the calculated results from the theoretical equation of pure water (Eq. 3). It can be seen from these figures that the trained values are in good agreement with the experimental data, while, the calcu lated values using Eq. 3 show a slight variation in both cases. The variation in calculated values can be attributed to the change of dynamic $v$ iscosity of nanofluid. A comparison of the experimental and ANN predicted values of the pressure drop $\Delta \mathrm{P}$ for all training data set of $21 \mathrm{~nm}$ and $95 \mathrm{~nm}$ nanoparticles are shown in Figs. 5 and 6, respectively. Also, included in these figures are straight lines indicating the perfect prediction to evaluate the accuracy of the ANN model predictions. It is evident from these figures that excellent agreement in accord with all experimental measurements of Duang thongsuk and Wongwises $(2009 ; 2010)$ and He et al. (2007) as well as the perfect prediction straight lines. It can be safely concluded that the proposed ANN model behaves well in the training stage and, therefore, is expected to exhibit a satisfactory performance in the validation stage as seen in the next section.

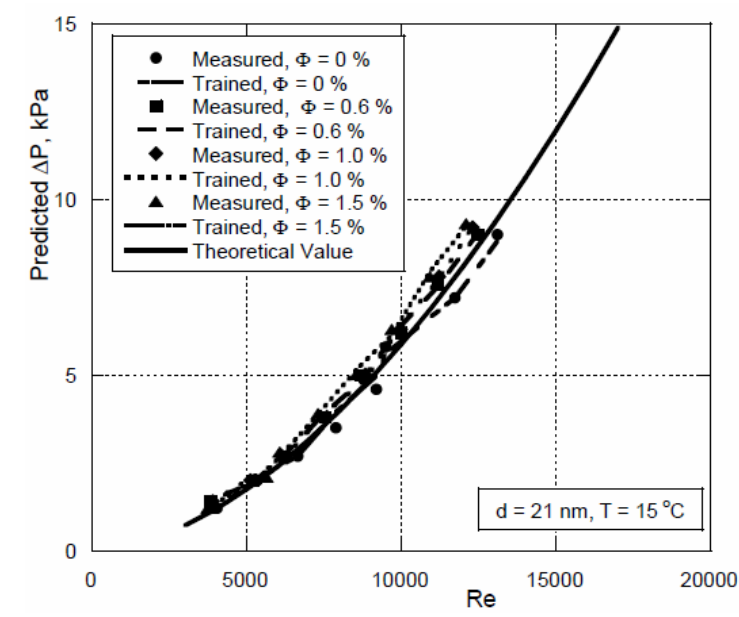

Fig. 2: Comparison of ANN-predicted values of pressure drop $\Delta \mathrm{P}$ with Reynolds number Re for the training data set.

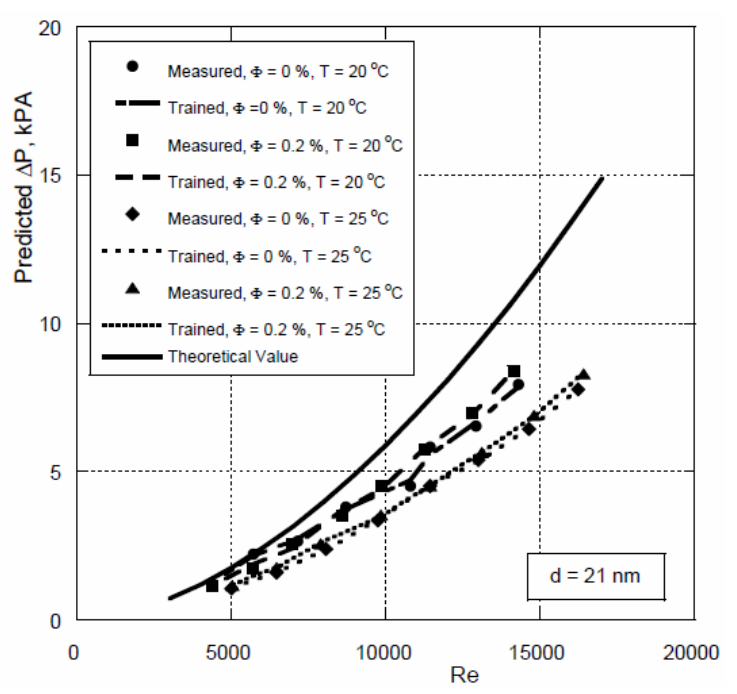

Fig. 3: Comparison of ANN-predicted values of pressure drop $\Delta \mathrm{P}$ with Reynolds number Re for the training data set.

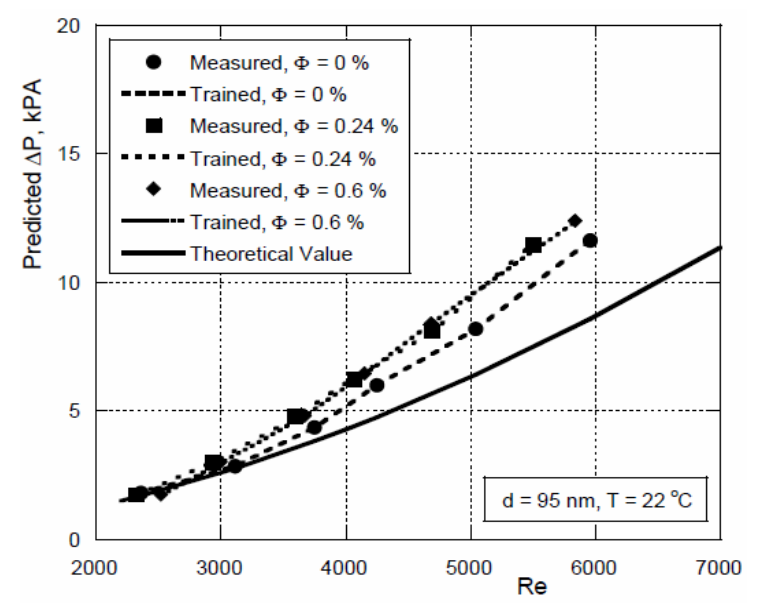

Fig. 4: Comparison of ANN-predicted values of pressure drop $\Delta \mathrm{P}$ with Reynolds number Re for the training data set 


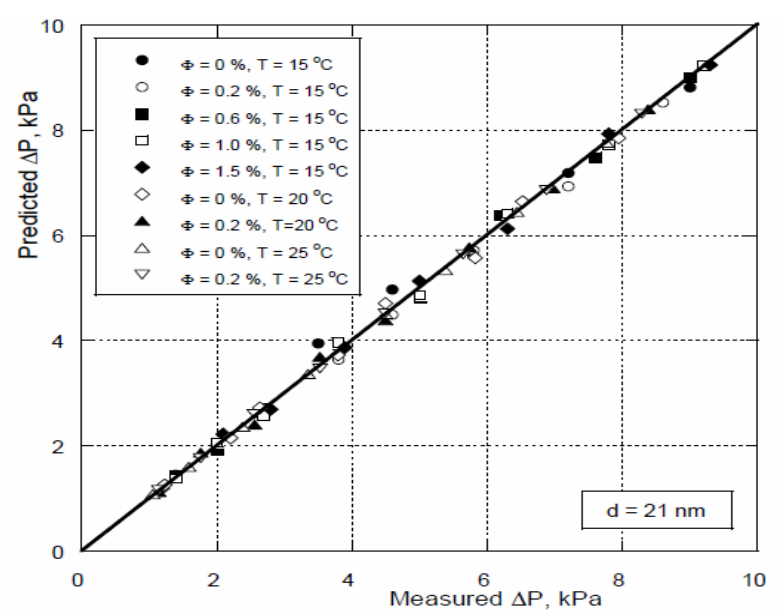

Fig. 5: Comparison of experimentally measured and ANN-predicted values of pressure drop $\Delta \mathrm{P}$ for the training data set.

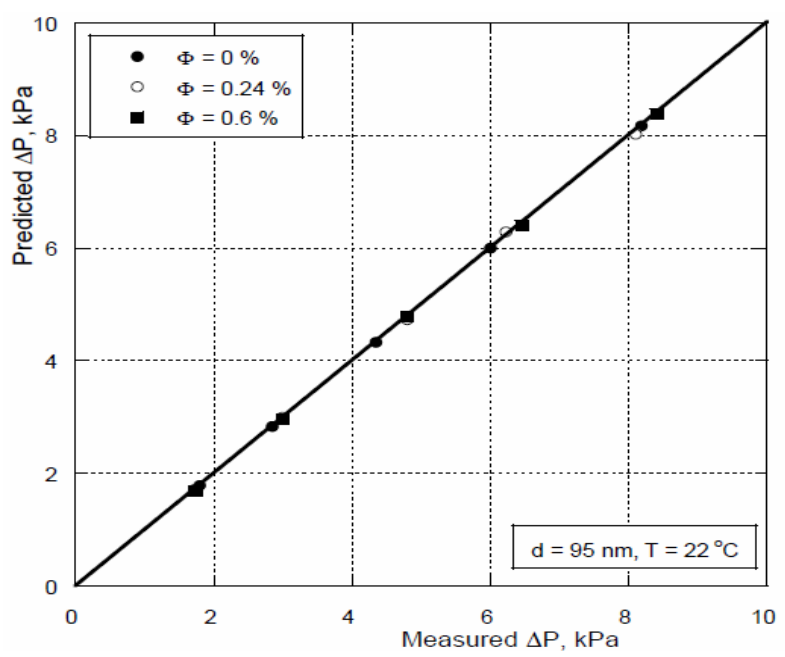

Fig. 6: Comparison of experimentally measured and ANN-predicted values of pressure drop $\Delta \mathrm{P}$ for the training data set

\subsection{Results of Validation}

To validate the proposed ANN model, a set of experimental data of $\mathrm{TiO}_{2}$-water for pressure drop as mentioned before was used. The predicted results of pressure drop, $\Delta \mathrm{P}$, from the $\mathrm{ANN}$ model were compared to the experimental measured data of Duangthongsuk and Wongwises (2009) as shown in Fig. 7. Also included in this figure arethe theoretical values of pressure drop obtained from the equation of singlephase fluid (Eq. 3). It was noticed from Fig. 7 that the predicted values of pressure drop were in good agreement with both the experimental data of Duangthongsuk and Wongwises (2009) and the calculated values using the theoretical equation for pure water (Eq. 3). To evaluate further the accuracy of the ANN model predictions, Fig. 8 shows another prediction performance measurement which a straight line indicating the perfect prediction is provided. Note that the comparisons shown in Figs. 7and 8, were made using the experimental values only from the test data set, which was not introduced to the ANN model during the training process as mentioned before and was selected randomly from experimentally obtained data set of Duangthongsuk and Wongwises (2009). It can be seen in Fig. 8 that the predicted results of pressure drop mimic almost the corresponding experimental results.

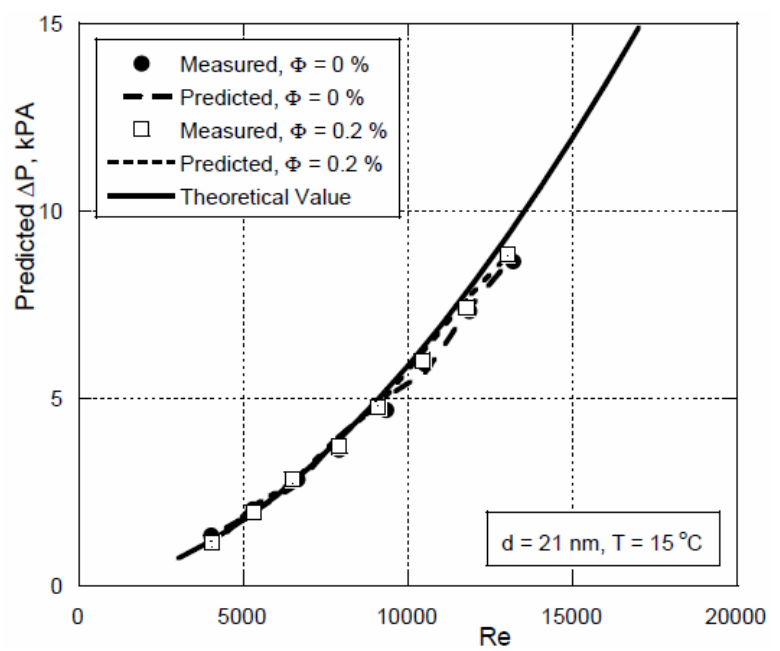

Fig. 7. Comparison of ANN-predicted values of pressure drop $\Delta \mathrm{P}$ with Reynolds number Re for the test data set.

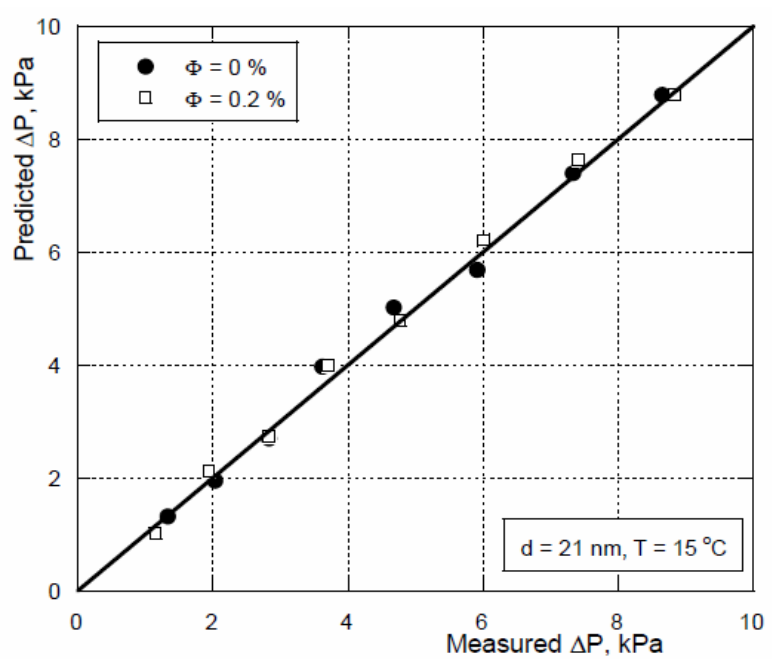

Fig. 8: Comparison of experimentally measured and ANNpredicted values of pressure drop $\Delta \mathrm{P}$ for the test data set

\section{Conclusion}

This study represented an ANN model to predict the pressure drop of $\mathrm{TiO}_{2}$-water flowing through a horizontal pipe under different turbulent flow conditions. Different experimental measured data with different particle volumetric concentrations, nanoparticle diameters, and nanofluid temperatures at different values of Reynolds number were used to construct the present ANN model. The ANN model based on a multilayer perception with error back propagation learning algorithm was developed. Excellent agreement between the predicted values and the experimental data at different parameters for 
pressure drop of $\mathrm{TiO}_{2}$-water nanofluid was observed. Moreover, acceptable agreement between the calculated values obtained from the theoretical equation for pressure drop of a single-phase fluid and the predicted values of the proposed ANN model was noticed. More experimental data for other nanofluids are needed to widen the range of application of the proposed ANN model.

\section{References}

[1] Aly, A. A., 2007 "Flow Rate Control of Variable Displacement Piston Pump With Pressure Compensation Using Neural Network" Journal of Engineering Science, Vol. 33, No. 1, pp. 199-209.

[2] Demir, H., Dalkilic, A. S., Kürekci, N. A., Duangthongsuk, W., and Wongwises, S., 2011 "Numerical investigation on the single phase forced convection heat transfer characteristics of $\mathrm{TiO}_{2}$ nanofluids in a double-tube counter flow heat transfer" International Communications in Heat and Mass Transfer, Vol. 38, pp. 218-228.

[3] Duangthongsuk, W. and Wongwises, S., 2009 " Heat transfer enhancement and pressure drop characteristics of $\mathrm{TiO}_{2}$-water nanofluid in a double-tube counter flow heat exchanger" International Joumal of Heat and Mass Transfer, Vol. 52, pp. 2059-2067.

[4] Duangthongsuk, W. and Wongwises, S., 2010 "An experimental study on the heat transfer and pressure drop of $\mathrm{TiO}_{2}$-water nanofluids flowing under a turbulent regime" International Journal of Heat and Mass Transfer, Vol. 53, pp. 334-344.

[5] Fard, M. H., Esfahany, M. N., and Talaie, M. R., 2010 "Numerical study of convective heat transfer of nanofluids in a circular tube two-phase model versus single-phase model" International Communications in Heat and Mass Transfer, Vol. 37, pp. 91-97.

[6] Fotukain, S. M. and Esfahany, M. N., 2010 "Experimental study of turbulent convective heat transfer and pressure drop of dilute $\mathrm{CuO}$ /water nanofluid inside a circular tube" International Communications in Heat and Mass Transfer, Vol. 37, pp. 214-219.

[7] He, Y., Jin, Y., Chen, H., Ding, Y., Cang, D., and Lu, H., 2007 "Heat transfer and flow behavior of aqueous suspensions of $\mathrm{TiO}_{2}$ nanoparticles (nanofluids) flowing upward through a vertical pipe" " International Joumal of Heat and Mass Transfer, Vol. 50, pp. 2272-2281.

[8] Hsu, K. L., Gupta, H. V., and Sorooshian, S., 1995 "Artificial neural network modeling of the rainfallrunoff process" Water Resources Research, Vol. 31, No. 10, pp. 2517-2530.
[9] Ko, G. H., Heo, K., Lee, K., Kim, D. S., Kim, C., Sohn, Y., and Choi, M., 2007 "An experimental study on the pressure drop of nanofluids containing carbon nanotubes in a horizontal tube" International Joumal of Heat and Mass Transfer, Vol. 50, pp. 4749-4753.

[10] Kondaraju, S., Jin, E. K., and Lee, J. S., 2010 "Direct numerical simulation of thermal conductivity of nanofluids: The effect of temperature two-way coupling and coagulation of particles" International Journal of Heat and Mass Transfer, Vol. 53, pp. 862-869.

[11] Kurt, H. and Kayfeci, M., 2009 "Prediction of thermal conductivity of ethylene glycol-water solutions by using artificial neural networks" Applied Energy, Vol. 86, pp. 2244-2248.

[12] Namburu, P. K., Das, D. K., Tanguturi, K. M., and Vajjha, R. S., 2009 "Numerical study of turbulent flow and heat transfer characteristics of nanofluids considering variable properties" International Journal of Thermal Sciences, Vol. 48, pp. 290-302.

[13] Peng, H., Ding, G., Jiang, W., Hu, H., and Gao, Y., 2009 "Measurement and correlation of frictional pressure drop of refrigerant-based nanofluid flow boiling inside a horizontal smooth tube" " International Journal of Refrigeration, Vol. 32, pp. 1756-1764.

[14] Saidur, R., Leong, K. Y., and Mohammad, H. A., 2011 "A review on applications and challenges of nanofluids" Renewable and Sustainable Energy Reviews, Vol. 15, pp. 1646-1668.

[15] Sajadi, A. R., and Kazemi, M. H., 2011"Investigation of turbulent convective heat transfer and pressure drop of $\mathrm{TiO}_{2}$ /water nanofluid in circular tube" International Communications in Heat and Mass Transfer, Vol. 38, pp. 1474-1478.

[16] Teng, T. P., Hung, Y. H., Jwo, C. S., Chen, C. C., and Jeng, L. Y., 2011 "Pressure drop of $\mathrm{TiO}_{2}$ nanofluid in circular pipes" Particuology, Vol. 9, pp. 486-491.

[17] Vajjha, R. S., Das, D. K., and Kulkarni, D. P., 2010 "Development of new correlations for convective heat transfer and friction factor in turbulent regime for nanofluids" International Journal of Heat and Mass Transfer, Vol. 53, pp. 4607-4618.

[18] Yu, W., France, D. M., Choi, S. U. S., and Routbort, J. L., 2007 "Review and assessment of nanofluid Technology for transportation and other applications" Energy Systems Division, Argonne National Laboratory. 


\section{Authors' Profiles}

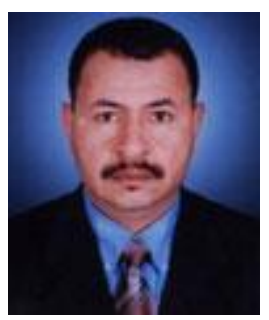

Dr. M. S. Youssef is the secretary of College Accreditation Steering Committee, College of Engineering, Taif University, Saudi Arabia since 2010 until now. He is also the chairman of Mechanical Engineering Program Committee, College of Engineering, Taif University, since 2010 until now. Dr. Youssef graduated in Mech. Eng. Dept., Assiut University, Egypt in 1983 and worked as Demonstrator and got his M. Sc. in 1989 from the same department. He got his Ph. D. from Nagoya Institute of Technology, Japan in 1994. Since 1995 He rejoined with Mech. Eng. Dept. of Assiut University as an Assistant Professor and promoted to Associate Professor in 2003. Dr. Youssef is currently on sabbatical leave of Assiut University. His research interest areas are turbulence modeling and computational fluid dynamics, development of numerical modeling techniques for the treatment of turbulent flows, liquid atomization and spray systems, and Nanofluids and their Modeling and Applications.

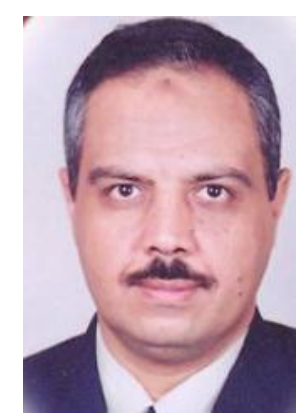

Dr. Ayman A. Aly, B.Sc. with excellent honor degree (top student), 1991 and M.Sc. in Sliding Mode Control from Mech., Eng., Dept., Assiut University, Egypt, 1996 and PhD. in Adaptive Fuzzy Control from Yamanashi University, Japan, 2003.

Nowadays, he is the head of Mechatronics Section at Taif University, Saudi Arabia since 2008. Prior to join ing Taif University, He is also one of the team who established the "Mechatronics and Robotics Engineering" Educational Program in Assiut University in 2006. He was in the Managing and Implementation team of the Project "Development of Mechatronics Courses for Undergraduate Program" DMCUP Project-HEEPF Grant A-085-10 Ministry of Higher Education - Egypt, 2004-2006.

The international biographical center in Cambridge, England selected Ayman A. Aly as international educator of the year 2012. Also, Ayman A. Aly was selected for inclusion in Marquis Who's Who in the World, 30 ${ }^{\text {th }}$ Pearl Anniversary Edition, 2013.

In additions to 5 text books, Ayman A. Aly is the author of more than 60 scientific papers in Refereed Journals and International Conferences. He supervised some of MSc and PhD Degree Students and managed a number of funded research projects.

Prizes and scholarships awarded: The prize of Prof. Dr. Ramadan Sadek in Mechanical Engineering (top student), 1989, The prize of Prof. Dr. Talet Hafez in
Mechanical Design 1990, Egyptian Government Scholarship 1999-2000, Japanese Government Scholarships (MONBUSHO), 2001-2002 and JASSO, 2011. The prize of Taif University for scientific research, 2012

Research interests: Robust and Intelligent Control of Mechatronics Systems, Automotive Control Systems, Thermo fluid Systems Modeling and Simulation.

How to cite this paper: M. S. Youssef, Ayman A. Aly,"Artificial Neural Network Turbulent Modeling for Predicting the Pressure Drop of Nanofluid", International Journal of Information Technology and Computer Science(IJITCS), vol.5, no.11, pp.13-20, 2013. DOI: 10.5815/ijitcs.2013.11.02 